\title{
Analisa Laju Korosi dan Kekerasan Pada Stainless Steel 316 L Dalam Larutan 10 \% NaCl Dengan Variasi Waktu Perendaman
}

\author{
Arga Jeremia Sinaga ${ }^{1,}$, Sutan L.M.H Simanjuntak ${ }^{2}$, Charles S.P Manurung ${ }^{2}$ \\ ${ }^{1}$ Mahasiswa Prodi Teknik Mesin, Universitas HKBP Nommensen, Medan-Indonesia \\ ${ }^{2}$ Dosen Prodi Teknik Mesin, Universitas HKBP Nommensen, Medan-Indonesia
}

\begin{abstract}
Corrosion is an electrochemical reaction between metals and the environment that causes corrosion and decreases the quality of metals. Steel is a metal material that is widely applied in the industrial world. Stainless steel is stainless steel that is resistant to corrosion because it has an alloying element of at least $18 \%$ chrome and $8 \%$ nickel. To find out the superiority of stainless steel as a construction material, research on local corrosion of stainless steel needs to be done. For this reason, research on corrosion is carried out by using a $10 \% \mathrm{NaCl}$ salt solution by varying the immersion time of stainless steel in corrosive media. From the research results it is known that the type of corrosion that occurs in specimens is the type of uniform corrosion. Likewise with the value of violence will decrease if the stainless steel is soaked longer.
\end{abstract}

Keywords : corrosion rate, hardness, 316L, $10 \% \mathrm{NaCl}$, soaking time

\section{PENDAHULUAN}

Dalam dunia industri, barang hasil produksi dibuat dan dirancang supaya memiliki ketahanan yang baik terhadap lingkungan, terutama produk yang berbahan logam. Logam merupakan salah satu jenis bahan yang banyak dimanfaatkan dalam peralatan penunjang bagi kehidupan manusia. Suatu logam dapat mengalami kerusakan akibat adanya korosi. Korosi merupakan reaksi elektrokimia antara logam dan lingkungan yang menyebabkan pengkaratan dan menurunkan mutu logam. Korosi merupakan sesuatu yang sangat berbahaya, baik secara langsung maupun tidak langsung.

Baja merupakan salah satu material logam yang banyak diaplikasikan dalam dunia industri. Ketahanan korosi pada baja dipengaruhi oleh unsur paduan yang terkandung di dalamnya seperti nikel (Ni), krom (Cr), dan mangan (Mn). Ketiga unsur tersebut akan berdampak pada sifat ketahanan korosi. Baja nikel laterit adalah baja yang diolah dari bijih nikel laterit kadar rendah. Baja ini dapat digolongkan ke dalam baja paduan rendah dengan kandungan nikel dan kromium lebih sedikit dibandingkan stainless steel. Stainless steel merupakan baja anti karat yang tahan terhadap korosi karena memiliki unsur paduan minimal $18 \%$ krom dan $8 \%$ nikel. Stainless steel dapat diperoleh dengan mencampurkan feronikel (18-20\% Ni. $75-78 \%$ Fe) ke dalam leburan nikel ferokrom melalui oksidasi sebelum dilakukan proses pembuatan baja. Feronikel yang ditambahkan disesuaikan dengan kandungan nikel yang terdapat dalam nikel ferokrom.

Berdasarkan struktur kristalnya, baja tahan karat dikelompokkan menjadi lima yaitu baja tahan karat austenitik, baja tahan karat feritik, baja tahan karat martensitik, baja tahan karat dupleks, dan baja tahan karat pengerasan pengendapan.

Baja tahan karat austenitik adalah baja yang mempunyai ketahanan korosi baik, sifat mampu bentuk, dan sifat mampu las serta bersifat non feromagnetik. Pada suhu 
rendah sering dimanfaatkan dalam aplikasi kriogenik. Baja tahan karat austenitik yang mengandung kromium dan nikel diberi nomor seri 300 dan seri 200 untuk kromium, nikel, dan mangan. Meskipun stainless steel merupakan baja tahan karat, tetapi masih dapat terserang korosi. Korosi yang terjadi dapat berupa korosi batas butir (intergranular corrosion), korosi lubang (crevice corrosion), korosi sumuran (pitting corrosion), dan korosi retak tegang (stress corrosion cracking). Untuk mengetahui keunggulan austenitic stainless steel sebagai bahan konstruksi, perlu dilakukan penelitian mengenai korosi lokal dari stainless steel tersebut. Penelitian mengenai korosi dilakukan dengan cara mereaksikan stainless steel dalam media korosif seperti larutan garam $(\mathrm{NaCl})$.

\section{METODOLOGI}

\subsection{Laju Korosi}

Laju korosi merupakan suatu besaran yang menyatakan cepat atau lambat suatu material bereaksi dengan lingkungannya dan mengalami korosi. Menurut Fontana (1978) dalam bukunya "Corrosion Engineering", laju korosi dapat didefinisikan dalam berbagai macam, seperti persentase kehilangan massa, miligram per sentimeter persegi per hari dan gram per inci persegi per jam. Selain itu, juga digunakan mils per year (mpy) yang menyatakan laju penetrasi serangan korosi terhadap logam. Laju korosi berbanding lurus dengan sejumlah arus yang mengalir pada sel korosi elektrokimia. Jika arus dapat diukur, suatu perhitungan yang tepat dari kehilangan logam akibat korosi dapat ditentukan.Ini berarti bahwa suatu pengukuran dalam ampere atau milliampere secara matematis dihitung dalam kilogram (pound) per tahun. Suatu Amp/tahun adalah satu Ampere yang mengalir selama periode satu tahun.

Untuk menghitung laju korosi, terdapat dua metode yang dapat digunakan antara lain metode kehilangan berat atau weight gain loss (WGL) dan metode elektrokimia. Metode kehilangan berat secara umum dianggap identik dengan kehilangan massa (mass loss). Metode kehilangan massa (mass loss) ini didasarkan pada selisih massa awal sebelum pengujian korosi dengan massa akhir setelah pengujian korosi. Jika diketahui penurunan masa dari suatu material yang terkorosi maka laju korosi dapat dihitung dengan menggunakan rumus sebagai berikut:

dimana:

$$
\mathrm{Cr}=\frac{534 B h}{\rho . t . L p} \quad \ldots .1
$$

$\mathrm{Cr}($ Corrosion rate $)=$ Laju korosi dalam satuan mpy $($ mils per year $)(\mathrm{mm} / \mathrm{y})$

$\mathrm{Bh}=$ Massa yang hilang $(\mathrm{mg})$

Lp = Luas sampel yang terendam $\left(i n^{2}\right)$

$\mathrm{t} \quad=$ Waktu perendaman (jam)

$\rho=$ Massa jenis logam $\left(\mathrm{g} / \mathrm{cm}^{3}\right)$

$1 \mathrm{mpy}=0,0254 \mathrm{~mm} / \mathrm{y}=25,4 \mu \mathrm{m} / \mathrm{y}=2,9 \mathrm{~nm} / \mathrm{hr}=0,805 \mathrm{pm} / \mathrm{sec}$

\subsection{Uji Kekerasan Vickers}

Uji kekerasan vickers menggunakan penumbuk piramida intan yang dasarnya berbentuk bujur sangkar. Besarnya sudut antara permukaan - permukaan piramida yang saling berhadapan adalah $136^{\circ}$.Karena bentuk penumbuknya piramida, maka pengujian ini sering dinamakan uji kekerasan piramida intan. Angka kekerasan vickers (VHN) didefinisikan sebagai beban dibagi luas permukaan lekukan. Pada prakteknya luas ini dihitung dari pengukuran mikroskopik panjang diagonal jejak. VHN dapat ditentukan dari persamaan berikut ini. 


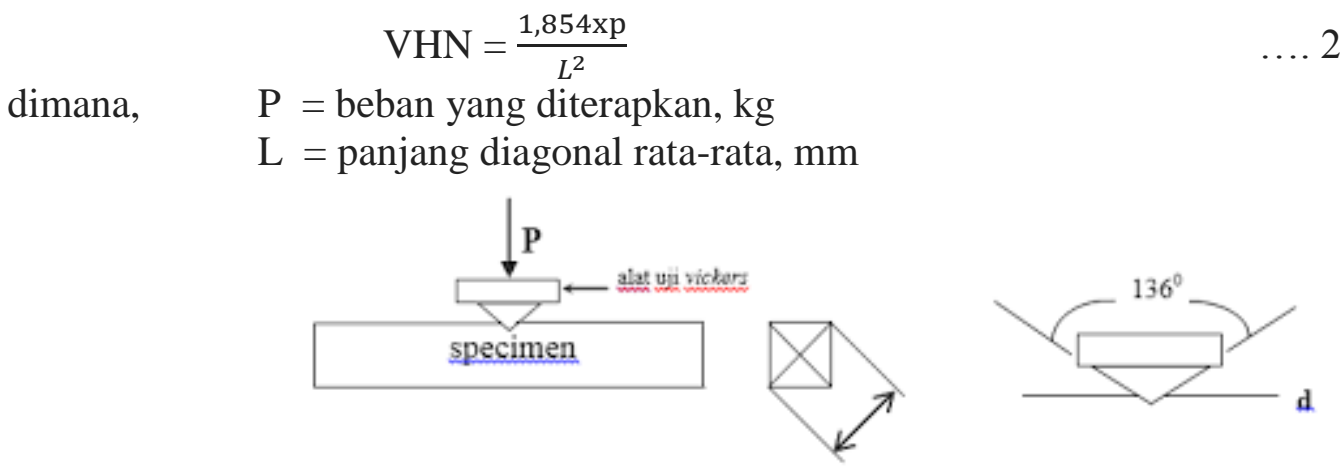

Gambar 1. Skema pengujan Vickers hardness

\subsection{Larutan $\mathrm{NaCl}$}

Natrium klorida, juga dikenal dengan garam dapur, adalah senyawa kimia dengan rumus molekul NaCl, mewakili perbandingan 1:1 ion natrium dan klorida. Dengan massa molar masing-masing 22,99 dan 35,45 g/mol, $100 \mathrm{~g} \mathrm{NaCl}$ mengandung 39,34 g Na dan 60,66 g Cl. Senyawa ini adalah garam yang paling memengaruhi salinitas laut dan cairan ekstraselular pada banyak organisme multiseluler. Pada penelitian ini digunakan larutan dengan kadar 10\% $\mathrm{NaCl}$. Larutan ini diperoleh dengan pencampuran antara $\mathrm{NaCl}$ (garam dapur) dengan air, dengan komposisi 10\% (10 gr) $\mathrm{NaCl}$ dan 90\% air.

\subsection{Stainless Steel 316L}

Stainless steel 316 L adalah stainless steel molibdenum austenitic. Kandungan nikel dan molibdenum yang lebih tinggi di kelas ini memungkinkannya untuk menunjukkan sifat tahan korosi keseluruhan yang lebih baik daripada 304, terutama yang berkaitan dengan korosi pitting dan celah di lingkungan klorida. Selain itu, Alloy 316L memberikan kekuatan tarik, creep, dan tegangan pecah suhu yang sangat baik, serta kemampuan bentuk dan kemampuan las yang luar biasa. 316L adalah versi karbon yang lebih rendah dari 316 dan kebal dari kepekaan; oleh karena itu, sangat sering digunakan dalam komponen yang dilas berat.

Tabel 1. Komposisi Stainless Steel $316 \mathrm{~L}$

\begin{tabular}{|l|l|l|l|l|l|l|l|l|}
\hline C & SI & S & P & MN & NI & CR & MO & FE \\
\hline 0,029 & 0,390 & 0,035 & 0,050 & 1,648 & 9,930 & 16,860 & 2,057 & - \\
\hline
\end{tabular}

Tabel 2. Sifat Mekanik SS 316L

\begin{tabular}{|l|c|l|l|l|l|l|l|}
\hline $\begin{array}{c}\text { Tensile } \\
(\mathrm{MPa})\end{array}$ & $\begin{array}{c}\text { Yield } \\
(\mathrm{MPa})\end{array}$ & $\begin{array}{c}\text { Elongation } \\
(\% \text { in50mm })\end{array}$ & $\begin{array}{c}\text { Hardness } \\
\text { Rocwell } \\
(\mathrm{HRB})\end{array}$ & $\begin{array}{c}\text { Density } \\
\left(\mathrm{kg} / \mathrm{m}^{3}\right)\end{array}$ & $\begin{array}{c}\text { Elastic } \\
\text { Modulus } \\
(\mathrm{GPa})\end{array}$ & $\begin{array}{c}\text { Specific } \\
\text { Heat } \\
(\mathrm{J} / \mathrm{Kg} . \mathrm{K})\end{array}$ & $\begin{array}{c}\text { Electric } \\
\text { Resistivity } \\
(\mathrm{n} \Omega . \mathrm{m})\end{array}$ \\
\hline 485 & 170 & 40 & 95 & 8000 & 193 & 500 & 740 \\
\hline
\end{tabular}




\subsection{Diagram Alir}

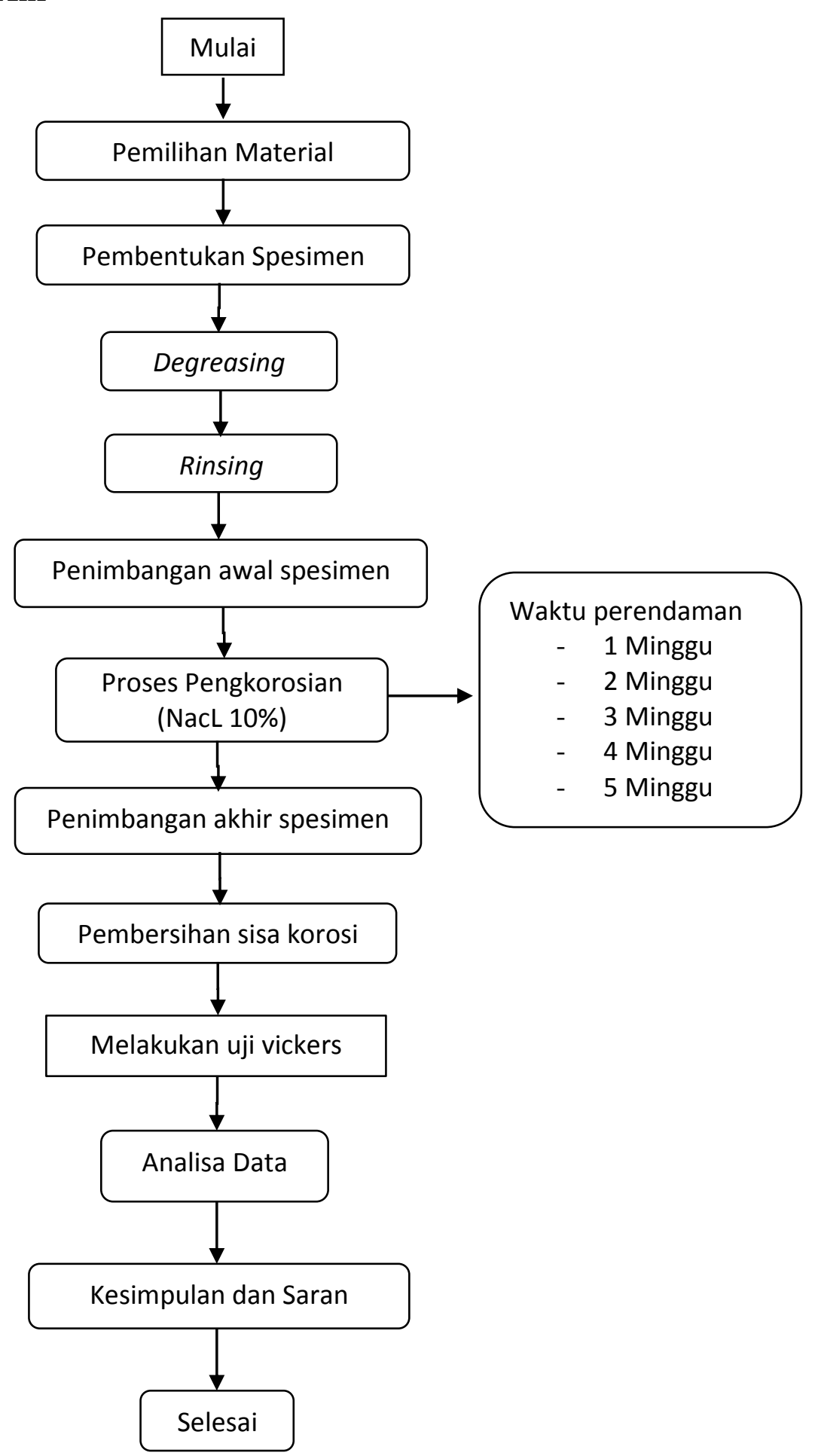

\section{HASIL DAN PEMBAHASAN}

\subsection{Hasil}

Benda kerja sebelum dan yang telah terkorosi kemudian ditimbang kembali, dengan alat timbang yang namanya Nautical Balance, Untuk mengetahui kehilangan 
berat dari benda kerja yang telah mengalami proses pengkorosian, kita dapat menghitung secara matematis dengan menggunakan rumus sebagai berikut :

$$
\mathrm{W}=\mathrm{W}_{0}-\mathrm{W}_{1}
$$

dimana: $\mathrm{W}=$ Pengurangan Berat $(\mathrm{mg})$

$$
\begin{aligned}
& \mathrm{W}_{0}=\text { Berat Awal (gr) } \\
& \mathrm{W}_{1}=\text { Berat Akhir (gr) }
\end{aligned}
$$

\begin{tabular}{|c|c|c|c|c|c|}
\hline $\begin{array}{l}\text { Spesim } \\
\text { en }\end{array}$ & $\begin{array}{c}\text { Waktu } \\
\text { Pencelupan } \\
\text { Spesimen }\end{array}$ & $\begin{array}{c}\text { Waktu } \\
\text { Pengangkatan } \\
\text { Spesimen }\end{array}$ & $\begin{array}{c}\text { Berat Awal } \\
\text { Spesimen } \\
\mathrm{W}_{0}(\mathrm{gr})\end{array}$ & $\begin{array}{c}\text { Berat Akhir } \\
\text { Spesimen } \\
W_{1}(\text { gr })\end{array}$ & $\begin{array}{l}\text { Selisih } \\
\text { Berat W } \\
\text { (gr) }\end{array}$ \\
\hline I & \multirow{2}{*}{$\begin{array}{l}\text { Kamis,9Januari2 } \\
020\end{array}$} & \multirow{2}{*}{$\begin{array}{l}\text { Kamis,16 Januari } \\
2020\end{array}$} & 15.75 & 15.60 & 0.05 \\
\hline II & & & 16.13 & 16.09 & 0,04 \\
\hline III & \multirow{2}{*}{$\begin{array}{l}\text { Kamis,9Januari2 } \\
020\end{array}$} & \multirow{2}{*}{$\begin{array}{l}\text { Kamis,23 Januari } \\
2020\end{array}$} & 16.15 & 16.04 & 0.11 \\
\hline IV & & & 15.98 & 15.88 & 0.10 \\
\hline V & \multirow{2}{*}{$\begin{array}{l}\text { Kamis,19 } \\
\text { Desember } 2019\end{array}$} & \multirow{2}{*}{$\begin{array}{l}\text { Kamis,09 Januari } \\
2020\end{array}$} & 15,76 & 15.61 & 0.15 \\
\hline VI & & & 16.08 & 15.91 & 0.17 \\
\hline VII & \multirow{2}{*}{$\begin{array}{l}\text { Kamis, } 19 \\
\text { Desember } 2019\end{array}$} & \multirow{2}{*}{$\begin{array}{l}\text { Kamis,09 Januari } \\
2020\end{array}$} & 15.54 & 15.34 & 0.20 \\
\hline VIII & & & 15.74 & 15.53 & 0.21 \\
\hline IX & \multirow{2}{*}{$\begin{array}{l}\text { Kamis, } 19 \\
\text { Desember } 2019\end{array}$} & \multirow{2}{*}{$\begin{array}{l}\text { Kamis,09 Januari } \\
2020\end{array}$} & 16.08 & 15.83 & 0.25 \\
\hline$X$ & & & 16.06 & 15.83 & 0.24 \\
\hline
\end{tabular}

Dengan menggunakan rumus di atas maka diperoleh data pada tabel berikut :

Tabel 3. Berat Spesimen Sebelum dan Sesudah Direndam

Setelah ditimbang, specimen hasil korosi kemudian dibersihkan dan dilakukan uji Vickers yang hasilmnya dapat dilihat pada tabel berikut ini.

Tabel 4. Kekerasan Spesimen Setelah Direndam

\begin{tabular}{|c|c|c|}
\hline Spesimen & \multirow{2}{\text{Waktu}}{$\begin{array}{c}\text { VHN (MPa) } \\
\text { (minggu) }\end{array}$} & \\
\hline I & 1 & 544,85 \\
\hline II & & 517,85 \\
\hline III & \multirow{2}{*}{2} & 477,34 \\
\hline IV & & 420,67 \\
\hline V & \multirow{2}{*}{3} & 439,46 \\
\hline VI & & 463,72 \\
\hline VII & \multirow{2}{*}{4} & 402,49 \\
\hline VII & & 376,13 \\
\hline IX & \multirow{2}{*}{5} & 354,59 \\
\hline X & & 380,60 \\
\hline
\end{tabular}

Tabel 5. Rata-rata nilai kekerasan pada speimen

\begin{tabular}{|c|l|c|}
\hline Material & Waktu perendaman & $\begin{array}{c}\text { Rata-rata } \\
\text { kekerasan VHN }\end{array}$ \\
\hline \multirow{3}{*}{ Stainless Steel } & Sebelum direndam & 624,35 \\
\cline { 2 - 3 } 316L & 1 minggu & 531,35 \\
\cline { 2 - 3 } & 2 minggu & 449,00 \\
\cline { 2 - 3 } & 3 minggu & 451,59 \\
\cline { 2 - 3 } & 4 minggu & 389,31 \\
\cline { 2 - 3 } & 5 minggu & 367,595 \\
\hline
\end{tabular}




\subsection{Pembahasan}

Dari data penelitian ini dapat kita analisa laju korosi yang terjadi dengan menggunakan persamaan 1 , dimana data penelitian ini dapat kita lihat seperti pada tabel di bawah ini..

Tabel 4. Laju korosi spesimen

\begin{tabular}{|c|c|c|c|}
\hline No & $\begin{array}{c}\text { Spesi } \\
\text { men }\end{array}$ & $\begin{array}{l}\text { Waktu } \\
\text { (Jam) }\end{array}$ & Laju Korosi (mpy) \\
\hline 1 & I & \multirow[t]{2}{*}{168} & 7,46 \\
\hline 2 & II & & 5,96 \\
\hline 3 & III & \multirow[t]{2}{*}{336} & 8,20 \\
\hline 4 & IV & & 7,46 \\
\hline 5 & V & \multirow[t]{2}{*}{504} & 7,460 \\
\hline 6 & VI & & 8,454 \\
\hline 7 & VII & \multirow[t]{2}{*}{672} & 7,460 \\
\hline 8 & VII & & 7,833 \\
\hline 9 & IX & \multirow[t]{2}{*}{840} & 7,460 \\
\hline 10 & $X$ & & 7,161 \\
\hline
\end{tabular}

Tabel 5. Rata-rata laju korosi pada spesimen

\begin{tabular}{|c|l|c|}
\hline Material & $\begin{array}{l}\text { Waktu } \\
\text { perendaman }\end{array}$ & $\begin{array}{l}\text { Rata-rata laju } \\
\text { korosi (mpy) }\end{array}$ \\
\hline \multirow{4}{*}{$\begin{array}{c}\text { Stainless Steel } \\
316 \mathrm{~L}\end{array}$} & 1 minggu & 6,71 \\
\cline { 2 - 3 } & 2 minggu & 7,83 \\
\cline { 2 - 3 } & 3 minggu & 7,95 \\
\cline { 2 - 3 } & 4 minggu & 7,64 \\
\cline { 2 - 3 } & 5 minggu & 7,31 \\
\hline
\end{tabular}

Dari data pada tabel 5 diatas dapat digambarkan grafik laju korosi akibat pengaruh waktu perendaman untuk stainless steel $316 \mathrm{~L}$ seperti pada gambar berikut ini.

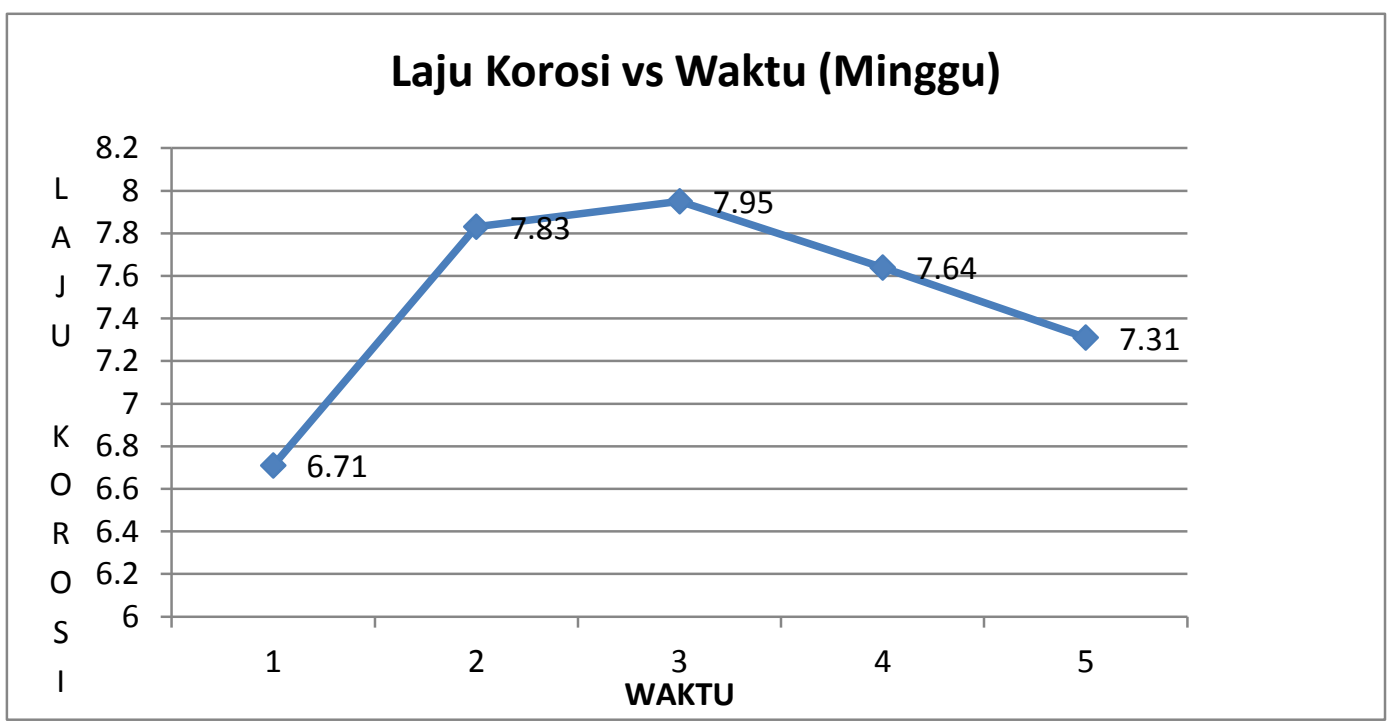

Gambar 2. Laju korosi akibat pengaruh waktu perendaman Stainless Steel 316L pada larutan $\mathrm{NaCl} 10 \%$. 
Dari grafik di atas dapat kita lihat bahwa laju korosi terjadi secara cepat pada minggu pertama sampai minggu ketiga, namun mengalami penurunan pada minggu ke empat dan lima.

Data hasil pengujian kekerasan seperti pada tabel 5 diatas dapat digambarkan grafik hubungan lamanya waktu perendaman dengan kekerasan specimen

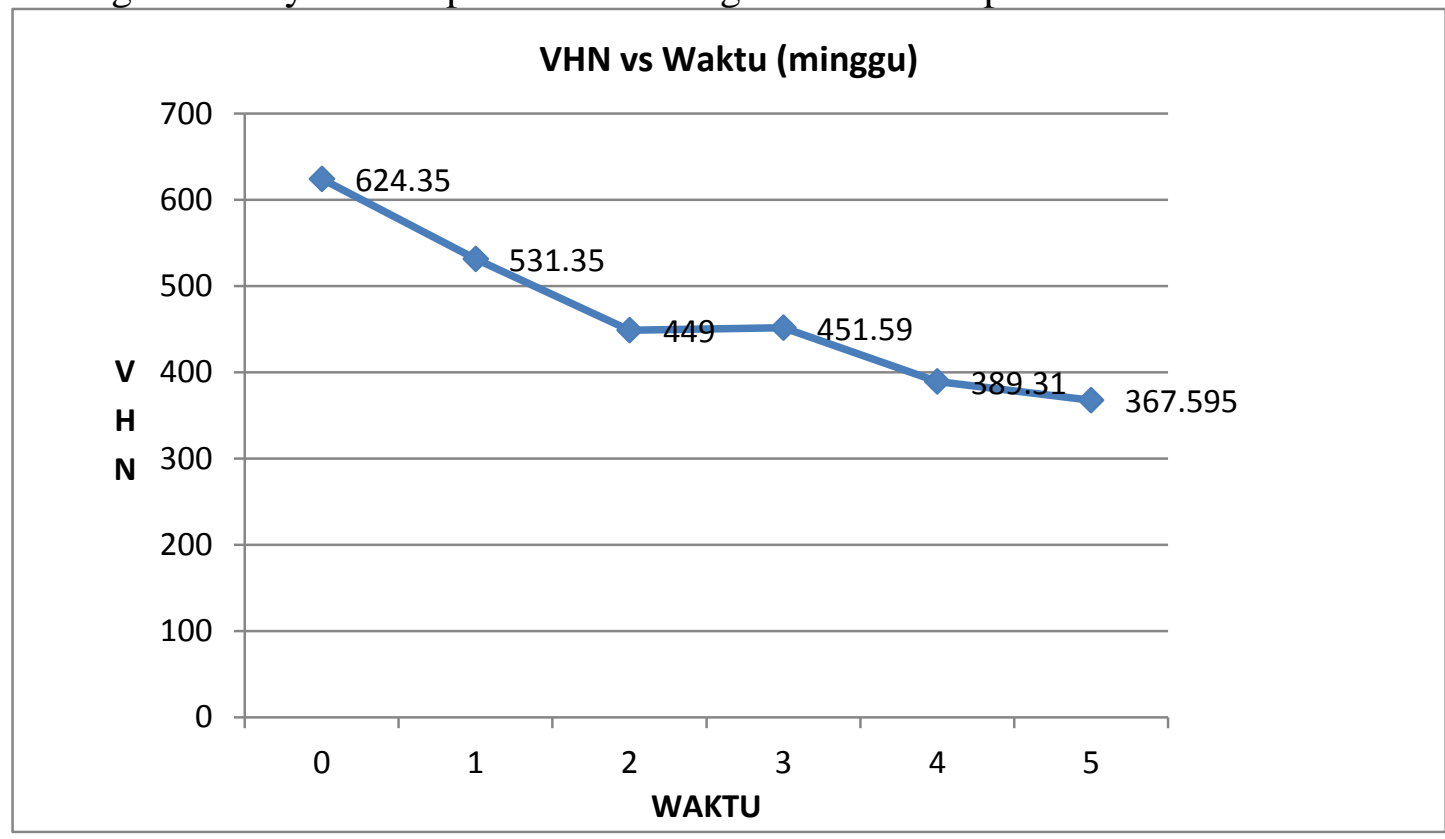

Gambar 3. Grafik hubungan lamanya waktu perendaman dengan kekerasan yang terjadi

\section{KESIMPULAN}

Dari hasil penelitian yang telah dilakukan, maka dapat disimpulkan bahwa jenis korosi yang terjadi pada spesimen adalah jenis korosi seragam (Uniform Corrosion). Karena pada setiap sisi dari spesimen mengalami perubahan warna atau terkorosi.Laju korosi yang terjadi pada material dipengaruhi oleh variable waktu yang diberikan pada saat proses pengkorosian, semakin lama waktu yang dipakai maka laju korosi semakin melambat. Hal ini dikarenakan adanya karat atau rush yang menghalangi proses korosi.

Nilai kekerasan pada dipengaruhi oleh lama perendaman material pada media korosi. Semakin lama material tersebut dikorosikan maka nilai kekerasan pada material tersebut juga akan semakin berkurang.

\section{DAFTAR PUSTAKA}

1. Yudha Kurniawan Afandi, Irfan Syarif Arief, dan Amiadji, Analisa Laju Korosi pada Pelat Baja Karbon dengan Variasi Ketebalan Coating, JURNAL TEKNIK ITS Vol. 4, No. 1, (2015)

2. Djoko Hadi Pratikno, Jan Setiawan, Elektrokimia Baja Tahan Karat SS 316 Dalam Media Nano Fluida, Jurnal Urania Vol. 25 No. 1, Februari 2019: 1-70

3. I.G. Ayu Arwati, Edy Herianto Majlan, Wan Ramli Wan Daud, Loh Kee, Temperature Effects on Stainless Steel 316L Corrosion in the Environment of Sulphuric Acid $\left(\mathrm{H}_{2} \mathrm{SO}_{4}\right)$, IOP Conf. Series: Materials Science and Engineering 343 (2018) 
4. R. Kohar, Laju dan bentuk korosi pada baja karbon menengah yang mendapat perlakuan pada suhu austenite diuji di dalam larutan $\mathrm{NaCl} 3 \mathrm{~N}$, Jurnal Desiminasi Teknologi, Volume 1, Nomor 1, Januari 2013

5. Afriwan Wahyu Pratama, Paridawati, Tri Santoso, Analisa laju korosi dan struktur mikro terhadap baja karbon rendah SS400 pada metode pelapisan hot dip galvanizing, Prosiding Seminar Nasional Energi dan Teknologi, UNISMA BEKASI, Juni 2019.

6. Wahyu Kheren Sabyantoro, Helmy Purwanto dan Muhammad Dzulfikar, Analisis laju korosi dengan aliran media korosi HCL 10\% pada material baja ASTM A36 dengan sudut bending, Momentum, Vol. 15, No. 1, April 2019 